\title{
Los Aportes de la Geografía en Estudios Turísticos
}

\author{
The contributions of Geography in Tourism studies
}

Noelia Aymara Padilla*

\section{RESUMEN}

La complejidad de la actividad turística produce la concurrencia de diversas disciplinas y perspectivas que contribuyen a su interpretación, aportando marcos conceptuales y metodológicos. El abordaje del turismo ha cambiado a lo largo de su desarrollo histórico y con la influencia de la Geografía. La investigación propone un análisis teórico de la vinculación entre Geografía y Turismo, a partir de una revisión del concepto de espacio turístico y su aplicación en estudios provenientes de la Geografía del Turismo.

Desde los autores tradicionales de la Geografía del Turismo, con sesgo economicista, los resultados permiten dar cuenta que la comprensión del espacio turístico se basa en la presencia y distribución territorial de los atractivos turísticos que representan la oferta. Desde un visón actual con influencia de la geografía Crítica y Posmoderna, el turismo es una práctica social que abarca mucho más que el desplazamiento físico entre dos lugares. Estos estudios incorporan los impactos territoriales de la actividad, tanto sociales como ambientales. Del análisis se concluye que el estudio del turismo con influencia de la Geografía permite incorporar la interrelación entre los fenómenos ambientales y los sociales, estudiando las cuestiones propias del mundo físico natural en su cercanía, epistémica y material, con los procesos sociales que origina el turismo en los espacios locales.

PALABRAS CLAVE: Geografía del Turismo. Espacio Turístico. Atractivos Turísticos.

\begin{abstract}
The complexity of the tourist activity produces the concurrence of diverse disciplines and perspectives that contribute to its interpretation, contributing conceptual and methodological frameworks. The tourism approach has changed throughout its historical development and with the influence of Geography. The research proposes a theoretical analysis of the link between Geography and Tourism, from a review of the concept of tourism space and its application in studies from the Geography of Tourism.

From the traditional authors of the Geography of Tourism, with economistic bias, the results allow to realize that the understanding of the tourist space is based on the presence and territorial distribution of the tourist attractions that represent the offer. From a current vision with influence of the critical and postmodern geography, tourism is a social practice that encompasses much more than the physical displacement between two places. These studies incorporate the territorial impacts of the activity, both social and environmental.

The analysis concludes that the study of tourism influenced by geography, allows to incorporate the interrelation between environmental and social phenomena, studying the issues of the natural physical world in its proximity, epistemic and material, with the social processes that originates the tourism in local spaces.
\end{abstract}

KEYWORDS: Geography of Tourism. Tourist Area. Tourist Attractions. 
Padilla, N. A.

\section{Introducción}

La complejidad de la actividad turística produce la concurrencia de diversas disciplinas y perspectivas que contribuyen a su interpretación, aportando marcos conceptuales y metodológicos. El abordaje del turismo ha cambiado a lo largo de su desarrollo histórico y con la influencia de la Geografía. La investigación propone un análisis teórico de la vinculación entre Geografía y Turismo, a partir de una revisión del concepto de espacio turístico y su aplicación en estudios provenientes de la Geografía del Turismo.

Guzmán Ramos y Fernández (2002) explican que la Geografía permite obtener un conocimiento integral del turismo, por la convergencia de vertientes sociales y ecológicas de otras disciplinas, permitiendo así alcanzar una visión integrada del espacio turístico. Asimismo, Salinas Chávez (2002) complementa que la Geografía admite superar algunas deficiencias teórico-metodológicas al estudiar el fenómeno turístico, especialmente las referidas a los límites de la actividad, basada en la síntesis geográfica y el análisis del fenómeno a diferentes escalas y considerando la diversidad espacial y ambiental de los destinos.

La Geografía es la ciencia que estudia el Espacio Geográfico, entendido como... "una totalidad estructural formada por un conjunto indisociable de sistema de objetos y de acciones" ... (SANTOS, 1994, p.90). Su esencia es social y está formado por las cosas, los objetos geográficos, naturales o artificiales, cuyo conjunto ofrece la naturaleza, más la sociedad. Cada fracción de la naturaleza abriga una fracción de la sociedad actual (SANTOS, 1997). La relación entre la sociedad y la naturaleza cobra importancia en la medida que la modifica la transformándola en una naturaleza humanizada.

Por su parte, la definición de turismo según la Organización Mundial del Turismo (OMT) (1999), incluye las actividades que realizan las personas durante sus viajes y estadías en lugares diferentes a su entorno habitual, por un período de tiempo consecutivo inferior a un año con fines de ocio, negocios y otros motivos no relacionados con el ejercicio de una actividad remunerada en el lugar visitado.

Salinas Chávez (2002) explica que el turismo no nació de una teoría, sino de un fenómeno social cuyo punto de partida es la existencia de tiempo libre o de ocio. Por su parte, para Jafari:

El turismo se define como el estudio del ser humano (el turista) cuando se encuentra lejos de su hábitat normal, de los equipamientos, las infraestructuras y las redes de servicios que han de satisfacer sus diversas necesidades y de los mundos "ordinario" (del que procede el turista) y 
"extraordinario" (al que viaja el turista), así como las relaciones dialécticas que se establecen entre ambos contextos (JAFARI, 2000, p.635)

\section{Metodología}

La investigación involucra un estudio teórico y aplica una metodología cualitativa que comprende las siguientes técnicas de obtención de datos:

Identificación de fuentes fundamentales de Geografía del Turismo en el abordaje del espacio turístico. El análisis comprende autores clásicos y modernos, provenientes tanto del Turismo como de la Geografía. Tuvo en cuenta entre ellos a: Boullón (1985) "Planificación del espacio turístico", Lozato-Giotart (1990) “Geographie du turisme. Dell 'espace regardé a l' espace consommé”, Callizo Soneiro (1991) “Aproximación a la Geografía del Turismo”, Vera Rebollo et al. (1997) “Análisis territorial del turismo. Una nueva geografía del turismo", Mesplier y BlocDuraffour (2000) “Geografía del Turismo en el mundo”, Barrado Timón y Calaguig (2001) “Geografía mundial del turismo", Bertoncello (2008) “Turismo y geografía. Lugares y patrimonio natural-cultural de la Argentina", entre otros.

- Reconocimiento de elementos que componen el Espacio Turístico y las diversas formas de interpretarlo. Incluye una revisión de artículos de revistas especializadas y libros desde el surgimiento de la Geografía del Turismo a la actualidad. Se analizó al espacio turístico como soporte, contenedor y producto de la actividad turística. Asimismo, el análisis incluye la relación con la conceptualización de Atractivos Turísticos por autores tradicionales del turismo y provenientes de la Geografía Crítica, Radical y Marxista.

La información se presenta estructurada en tres apartados. En el primero de ellos "La evolución de la Geografía del Turismo" se analiza el origen de esta rama de la Geografía, la influencia de corrientes epistemológicas, escuelas geográficas y sus enfoques hasta la actualidad. Incluye la relación con las principales plataformas del turismo que agrupan trabajos y perspectivas en Turismo. En el segundo y tercer apartado "El espacio turístico desde una visión tradicionalista" y "El espacio turístico desde la visión geográfica y crítica" se incluyen la conceptualización de algunos conceptos básicos de la Geografía del Turismo, entre ellos: Espacio Turístico y Atractivos Turísticos. 
Padilla, N. A.

\section{Resultados}

\section{La evolución de la Geografía del Turismo y su objeto de estudio}

La Geografía del Turismo tiene antecedentes en la Geografía Turística que se basa en la descripción de lugares y atractivos turísticos. Esta disciplina presenta un sesgo naturalista en la medida que privilegiaba el estudio de ambientes y paisajes naturales, desconociendo las relaciones sociedad-naturaleza, que constituyen la base de la Geografía Social (BALASTRERI RODRÍGUEZ, 2003). Su interés fundamentalmente es descriptivo propio del ejercicio de los inventarios y de los diagnósticos turísticos que son la base de procesos de explotación económica de los recursos de un lugar con potencial turístico. No busca explicar ni proponer modelos de organización territorial más acordes con las necesidades de sostenibilidad y con los intereses de las comunidades que habitaban los territorios.

Por su parte, el campo de la Geografía del Turismo es mucho más amplio y tiene una pretensión profundamente explicativa. Cassola (1982, p.19) afirma que la Geografía del Turismo es "[...] la ciencia que estudia las particularidades territoriales de la economía turística, la distribución territorial de las actividades de producción y servicios relacionadas con el turismo y las condiciones, factores y recursos que condicionan su desarrollo en diferentes países y regiones".

En este sentido, Pearce (1991) sostiene que la Geografía del Turismo tiene como objeto de estudio:

- los patrones de distribución espacial de la oferta;

- los patrones de distribución espacial de la demanda;

- la geografía de los centros vacacionales;

- los movimientos y flujos turísticos;

- el impacto del turismo;

- los modelos de desarrollo del espacio turístico.

Por su parte, según Cazes (1992) debe incluir los temas:

- Distribución. Comportamiento espacial demanda, movilidad y medios desplazamientos, flujos y conjuntos espaciales, fenómenos de difusión y distinción, estrategias de localización, distancias, entre otros. 
- Producción espacial turística imaginaria (percepción) y material (formas, tipos espaciales, modelos y técnicas de ordenación, paisajes construidos, espacialización de productos, entre otros).

- Articulación espacial del sistema turístico con el sistema local, modalidades imbricación del turismo en el territorio, turistificación, puesta en valor.

Finalmente, para Pinassi y Ecolani (2014, p.2013) "La Geografía del Turismo, como rama de la Geografía Humana, centra su análisis en el turismo y sus múltiples vinculaciones con el territorio".

En palabras de Vera Rebollo et al. (1997) hasta la década de los años cuarenta del pasado siglo predominaba la Geografía del Turismo como parte de la Geografía del Transporte y de las Comunicaciones. Los autores mencionan que fue ganando peso la inclusión de esta rama dentro del área de la Geografía Económica. Tanto en la Geografía Determinista como Posibilista, el objeto de estudio se centra en las influencias que los factores físicos y antropogeográficos tienen sobre la aparición y desarrollo del turismo.

Luego, en la Geografía Neopositivista, la Geografía del Turismo tiene como objeto de estudio el análisis de las regularidades existentes en la distribución de los asentamientos turísticos, que descansan sobre los principios de racionalidad económica. A partir de la década de los años setenta del pasado siglo, la Geografía del Turismo se desarrolla fuertemente, junto con el papel del ocio y del turismo en la producción económica y en la organización del espacio. Se destacan las producciones de Cazes (1992) en Francia, cuya obra puede dividirse según Seguí Linás (2006) en tres grandes bloques que van desde las primeras producciones a fines de la década de los años sesenta hasta la década de los años noventa: los análisis regionales del turismo, la relación turismo-tercer mundo y la epistemología del turismo, siendo los últimos estudios encaminados hacia el turismo urbano y todos sus temas conexos: las imágenes, el deseo y la cultura.

De acuerdo con lo establecido por Hiernaux a partir de la década de los años sesenta del pasado siglo, en la Geografía del Turismo se distinguen dos enfoques:

(...) por una parte, se desarrolló la escuela de origen marxista, siguiendo los patrones y formulaciones del marxismo estructuralista en boga. Por otra parte, estuvieron los trabajos de quienes analizaron críticamente el turismo desde sus impactos negativos (...) (HIERNAUX, 2006, p.414).

Esto involucró efectos en la sociedad, la naturaleza, las sociedades receptoras o en la configuración del espacio turístico. 
La evolución de la Geografía del Turismo, como se ha explicado, guarda relación con el desarrollo de la Geografía en general. Sin embargo, es notoria también, la relación con las diversas perspectivas históricas en torno al turismo. En base a los estudios de Jafari (2005), existen distintas plataformas del turismo, las cuales agrupan trabajos que representan la evolución de la reflexión sobre el turismo: Plataforma Apologética, Plataforma Precautoria, Plataforma Adaptativa y Plataforma Científico-Céntrica.

La primera de ellas considera que el turismo beneficia a muchos sectores económicos más allá de los directamente implicados en él, por ello es una alternativa viable para muchas comunidades y países. Bajo esta plataforma se subrayan sus atributos positivos, como contribuir a preservar el entorno natural y cultural, revivir antiguas tradiciones, mantener espectáculos culturales y facilitar la comunicación intercultural y las expectativas de paz mundial.

La Plataforma Precautoria aparece principalmente en la década de los años sesenta, a partir de la preocupación de algunas instituciones públicas y privadas, por la protección de la cultura y la naturaleza. Su mensaje está enfocado en la falta de beneficios económicos ligados al turismo, la generación de empleos principalmente estacionales y de baja calificación, los beneficios de las grandes empresas y culturas, los desequilibrios en las sociedades de acogida, entre otros.

En la Plataforma Adaptativa, la mayoría de los debates polarizados entre las plataformas anteriores que giraban en torno a los impactos (positivos y negativos) del turismo, se dirigen hacia formas de desarrollo alternativo. Los estudios favorecen a aquellos tipos de turismo respetuosos con las comunidades de acogida y su entorno sociocultural o construido, así como con el medio natural en el que se mueven. Aparecen nuevas modalidades turísticas: agroturismo, turismo apropiado, turismo comuno-céntrico, turismo controlado, turismo de granja, turismo cultural, turismo étnico, ecoturismo, turismo verde, turismo de naturaleza, turismo responsable, turismo rural, entre otras.

En la Plataforma Científico-Céntrica surge la consideración del turismo como un sistema. Se intenta mantener comunicación con las otras plataformas, siendo su meta la formación de un cuerpo científico de conocimiento sobre el turismo. Las antiguas definiciones de turismo, generalmente preocupadas por el número de kilómetros viajados, los motivos de viaje y el dinero gastado (Plataforma Apologética) han evolucionado hacia definiciones más totalizadoras que incluyen referencias a los sistemas generadores y receptores, su interdependencia y el texto y contexto que aseguran su vitalidad. 
Padilla, N. A.

En 1990, desde la perspectiva de Jafari (2005), comienza un abordaje académico multidisciplinar en donde la actividad turística es reconocida como un fenómeno complejo que debe ser analizado desde una visión holística y olvida la atención anterior en los aspectos de gestión empresarial. De esta forma, Barrado Timón y Calabuig (2001) menciona que frente a la visión económica, comienzan a estudiarse nuevos fenómenos como la progresiva segmentación de la demanda, tanto en lo referido a la búsqueda de productos novedosos, como a los ámbitos temporales en que se realiza la actividad, una creciente exigencia de calidad en turistas día a día más experimentados y conocedores de productos diversos, la preocupación por los aspectos ambientales o la necesidad de recalificar los productos y destinos maduros, junto con el aumento de la competencia a cualquier escala territorial.

\section{El espacio turístico desde una visión tradicionalista}

Desde una visión tradicionalista el espacio turístico se comprende como consecuencia de la presencia y distribución territorial de los atractivos turísticos (BOULLÓN, 1985). El análisis espacial del turismo según Cazes (1992), Lozato-Giotart (1990), Callizo Soneiro (1991), Vera Rebollo et al. (1997), Barrado Timón y Calabuig (2001), incluye el estudio de la diversidad geográfica de los flujos turísticos, la localización de los focos emisores y receptores, los factores de localización de la actividad turística o la diversidad de tipos de espacios de destino turístico (litorales, de montaña, rurales, entre otros), las modalidades de turismo asociadas, los atractivos y los efectos que el desarrollo del turismo provoca en los lugares de destino turístico. Para Almirón (2004) estos estudios presentan un fuerte sesgo descriptivo y empírico en sus análisis, teniendo a los anuarios estadísticos de turismo provistos por la OMT y otras instituciones vinculadas al turismo como fuente de información fundamental y el mapa como instrumento esencial para la espacialización del fenómeno.

Por otra parte, desde esta visión se acentúala utilización de clasificaciones y tipologías como importantes herramientas de análisis, son ejemplos de ellos, los informes presentados por la OMT o los estudios de Lozato-Giotart (1990) y Callizo Soneiro (1991) aplicadas al estudio de los flujos y focos turísticos o a los tipos y formas de espacios turísticos. Desde la postura de Almirón (2004), el énfasis está puesto en los datos estadísticos que vinculan oferta y demanda (salidas, llegadas, gastos, ingresos), la descripción de las características de los flujos que vinculan las áreas emisoras y receptoras, las características generales de las regiones emisoras y receptoras, y las singularidades de los destinos turísticos, particularmente 
Padilla, N. A.

en lo que hace a la enumeración y descripción de sus atractivos que definen la aptitud o vocación turística de los mismos.

El espacio turístico es un lugar geográfico determinado donde se asienta la oferta turística y hacia el que fluye la demanda (VERA REBOLLO et al., 1997), por ello, el turista es un elemento central que forma el flujo que vincula ambos lugares. De acuerdo con Almirón (2004), esta conceptualización remite a una noción de espacio turístico que se reduce a la idea de un espacio dividido en dos: sociedades emisoras y sociedades receptoras. Ambos se articulan por medio del viaje o desplazamiento de los turistas, consumándose así el hecho turístico.

Las problemáticas territoriales de carácter social producto de la relación del turismo con la actividad turística no presentan un análisis complejo, siendo mencionada en la enumeración de impactos positivos y negativos del turismo a la que concurren múltiples autores. Por su parte, la cuestión ambiental queda limitada a partir del reconocimiento de los factores de localización (incluyendo los naturales) o diversidad de espacios (litorales, montaña, rurales o urbanos).

Bajo esta visión tradicional, se definen algunos conceptos básicos del turismo: recurso turístico y atractivo turístico. El recurso turístico constituye el conjunto potencial (conocido o desconocido) de los elementos de la naturaleza y bienes materiales o inmateriales a disposición del hombre y que pueden utilizarse mediante un proceso de transformación, para satisfacer sus necesidades turísticas (OMT). Para Leno Cerro (1993) el recurso sólo es factible si existen ciertas atracciones, apreciables por su importancia cuantitativa o cualitativa que causen el desplazamiento del domicilio habitual para permanecer cierto tiempo fuera de él.

Según Domínguez de Nakayama (1993), los recursos turísticos deben cumplir tres condiciones básicas que definen la posibilidad de insertarse en la actividad turística: atractividad, aptitud y disponibilidad. El primero de ellos se relaciona con el valor estético y emocional de los recursos, es decir que combina aspectos de la oferta, como por ejemplo las cualidades intrínsecas, y aspectos de la demanda, como el conocimiento y la preferencia de los usuarios. La aptitud se refiere a la capacidad de uso de los bienes culturales y naturales y analiza su potencial para insertarse en la actividad turística. Finalmente, la disponibilidad se refiere a la accesibilidad física, temporal y administrativa.

Además, los atractivos pueden ser considerados como los elementos básicos, dado que constituyen la base sobre la que se sustenta la decisión de visitar ciertos destinos. La clasificación de los atractivos desarrollada por el Centro Interamericano de Capacitación 
Padilla, N. A.

Turística (CICATUR) en 1978 es una de las más utilizadas y cataloga a los atractivos turísticos en las siguientes categorías: sitios naturales; manifestaciones culturales; folklore; realizaciones técnicas, científicas o artísticas contemporáneas y acontecimientos programados. Cada una de estas categorías está desagregada en un conjunto de tipos y subtipos, y valorada según sus características esenciales.

De esta manera, según Boullón (1985), surgen los elementos componentes del espacio turístico identificados a partir de la cuantificación de atractivos, sin un análisis del contexto temporal o espacial:

a) zona turística: una unidad de análisis de rango superior que concentra como mínimo diez atractivos próximos y contiguos.

b) centro turístico: comprende un conglomerado urbano con atractivos turísticos de jerarquía suficiente para motivar el desplazamiento de ida y regreso durante el día.

A partir de la función que desempeñan los centros turísticos es posible distinguir los centros turísticos de estadía, que se basan en la explotación de un único atractivo, con una estadía superior a tres noches de alojamiento, por lo que requieren equipamiento recreativo diversificado; y los centros turísticos de distribución, que sirven de base al turista para visitar los atractivos próximos, pudiendo regresar en el mismo día a la ciudad de base.

\section{El espacio turístico desde la visión posmoderna}

Desde una visión geográfica y crítica el turismo tiene una naturaleza espacial pero además es un fenómeno territorial. Los espacios turísticos no sólo son escenarios en los cuales se ubican una serie de accidentes geográficos, elementos naturales, asentamientos humanos, manifestaciones de una cultura, generadores de actividades de intercambio económico; sino que es un territorio complejo, en el que tienen lugar multiplicidad de hechos: relaciones sociales, manifestaciones de territorialidad, el sentido de pertenencia, entre otros (ALMIRÓN, 2004). Según explican Pinassi y Ercolani (2014, p.219)," [...]la visión crítica de la geografía del turismo otorga otra connotación al territorio. Deja de ser mero portador de recursos turísticos, condicionantes de la actividad, y se transforma en un concepto socio espacial integrado" ...

Desde los abordajes críticos, el turismo, más que un simple desplazamiento físico entre dos lugares (emisor y receptor) es ante todo una práctica social, con implicancias territoriales específicas (ALMIRÓN, 2004). De esta manera, no se concibe pensar la práctica 
turística en forma independiente o desligada de los contextos sociales concretos en los cuales se lleva a cabo y, al mismo tiempo, en los cuales define sus especificidades. Bertoncello (2002) señala que insertar la práctica turística en procesos sociales más amplios resulta una tarea fundamental para avanzar en su conceptualización y compresión.

En este sentido, en palabras de Hiernaux (1996), el turismo como práctica colectiva integra mecanismos singulares de relación que afectan la identidad del espacio. Es por ello por lo que el espacio no sólo constituye el soporte de las actividades turísticas, sino de un conjunto de prácticas sociales que provienen del turismo, y que a la vez condicionan al espacio. En este sentido, la trialéctica espacial de Soja $(1985,1996)$, tal como explica Almirón (2004), analiza la espacialidad del turismo mediante la interconexión de los tres espacios identificados por el autor (vivido, concebido, percibido), en las cuales espacio y turismo interactúan, se entretejen y se influencian el uno sobre el otro.

Almirón (2004, p.10) menciona: “[...] es necesario poner el énfasis no en el lugar turístico en sí mismo (en sus singularidades y excepcionalidades, que de acuerdo con las tradicionales Geografías del Turismo son las que definen la aptitud o vocación turística de un lugar) sino en su proceso de construcción geográfica e histórica". Esto permitiría para la autora avanzar hacia una conceptualización del lugar turístico como producto de procesos sociales, subjetivos y cambiantes (históricos), en el que se articulan intereses, valores e imágenes (de las sociedades de origen de los turistas y de destino) con los atributos materiales del lugar.

En este sentido, la condición de atractividad turística de un lugar no resultaría de sus atributos intrínsecos sino de procesos de valorización social que definen cuáles de esos atributos o rasgos del lugar se transformarán en atractivos turísticos. Es por ello que los procesos sociales, las prácticas y los discursos sociales construyen los lugares turísticos y definen qué atributos del lugar se convertirán en atractivos turísticos, a través de su puesta en valor por imágenes, obras, discursos, modas, entre otros.

La relación con la Geografía Critica (Radical, Marxista) se hace presente, así como con la Geografía Posmoderna y las obras fundadoras de Harvey: The condition of postmodernity (1987) y Soja: Postmodern Geographies (1989) donde aparecen interrogantes sobre la dinámica del mundo actual y la necesaria reinserción de lo espacial en las ciencias sociales, y el reconocimiento de una aproximación tanto espacial como temporal en la comprensión de la vida social contemporánea. 
Padilla, N. A.

En concordancia con Hiernaux (1996), el desarrollo planificado y la ordenación integrada de los espacios turísticos deben garantizar de manera efectiva la inserción armónica del turismo en el medio local desde el punto de vista paisajístico, ambiental, económico y sociocultural. La planificación y gestión de los espacios turísticos debe tender a la optimización en el uso del espacio y basarse en el respeto a las comunidades receptoras, redistribuyendo una parte importante de los beneficios obtenidos en el territorio.

El giro cultural en la Geografía Humana sugiere recorrer nuevas orientaciones de análisis, sustentadas no sólo en un mayor hincapié en la dimensión cultural sino también en el individuo y sus prácticas turísticas en el espacio, en una Geografía más ligada a lo inmediato, lo cotidiano o lo trivial y a la corporeidad de las prácticas turísticas (HIERNAUX, 2008). En palabras de Pinassi y Ercolani (2014), se origina un quiebre en la visión fatalista de la geografía crítica del turismo y entran en juego nuevas variables que humanizan al turismo, ya sea desde la perspectiva del individuo o de su comportamiento socio espacial cotidiano. Se produce un cambio en la escala de análisis: interesa lo particular y habitual, antes que lo macro generalista.

Sin embargo, tal como explican Pinassi y Ercolani (2014), las publicaciones en revistas turísticas destacan aún artículos centrados específica y únicamente en estudios de impacto en el territorio (principalmente ambiental); de recursos turísticos o con potencialidad de desarrollo; de ordenamiento territorial; entre otros. No presentan una contextualización teórica o conceptual genérica previa y prevalecen los estudios de caso, antes que los aportes teóricos a la disciplina.

\section{Conclusión}

Del análisis se concluye que el estudio del turismo con influencia de la Geografía permite incorporar la interrelación entre los fenómenos ambientales y los sociales, estudiando las cuestiones propias del mundo físico natural en su cercanía, epistémica y material, con los procesos sociales que origina el turismo en los espacios locales. El espacio turístico como objeto de análisis y concepto ha evolucionado de soporte de las prácticas turísticas a una construcción social donde la relación del turismo con el territorio condiciona el espacio.

El análisis de los autores tradicionales de la Geografía del Turismo permite dar cuenta de la importancia de la dimensión económica, y del estudio de la presencia y distribución territorial de los atractivos turísticos (oferta). Este análisis incluye la identificación de flujos o 
localización de focos emisores y receptores. Las problemáticas territoriales de carácter social producto de la relación del turismo con la actividad turística no presentan un análisis complejo, siendo mencionada en la enumeración de impactos positivos y negativos del turismo a la que concurren múltiples autores. Por su parte, la cuestión ambiental queda limitada a partir del reconocimiento de los factores de localización (incluyendo los naturales) o diversidad de espacios (litorales, montaña, rurales o urbanos).

Desde una visión geográfica y crítica, el turismo es una práctica social que abarca mucho más que el desplazamiento físico entre dos lugares. La relación recíproca entre la sociedad y la naturaleza se hace presente y aparecen los efectos territoriales, incluyendo los impactos de tipo social y ambiental en el espacio. Desde el punto de vista ambiental, esta situación coincide con la aparición del Informe Brundtland de 1987 y la posterior Declaración de Río del año 1992, donde se introduce el concepto de Desarrollo Sustentable.

Desde el punto de vista social ello se corrobora con los paradigmas críticos de la Geografía que cobran predominancia a partir de la década de los años setenta con el surgimiento de la Geografía Radical. En la actualidad la influencia de una Geografía posmoderna y la reinserción de lo espacial en las ciencias sociales, incluyendo el turismo.

\section{Bibliografía}

ALMIRON, A. V. Turismo y espacio. Aportes para otra geografía del turismo. GEOUSP. Espaço e Tempo, São Paulo. $\mathrm{N}^{\mathrm{o}}$ 16, pp.166 -180, 2004. DOI: https://doi.org/10.11606/issn.2179-0892.geousp.2004.73963

BALASTRERI RODRÍGUEZ, A. Geografia do turismo: novos desafios. En: Como aprender turismo, como enseñar. Tercera edición. São Paulo, pp. 87-122, 2003.

BARRADO TIMÓN, D. y CALAGUIG, J. (editores). Geografía mundial del turismo. Madrid: Síntesis, 2001.

BERTONCELlO, R. Turismo y territorio. Otras prácticas, otras miradas. Aportes y transferencias, Año 6, Volumen 2. CIT-UNMDP. Mar del Plata, pp. 29-50, 2002.

Turismo y geografía: lugares y patrimonio natural-cultural de la Argentina. Buenos Aires, Ciccus, 2008, 272 pp, 2008. DOI: https://doi.org/10.11606/issn.21790892.geousp.2004.73963

BOULLÓN, R. Planificación del espacio turístico. España: Editorial Trillas, 1987.

CALLIZO SONEIRO, J. Aproximación a la Geografía del Turismo. España: Síntes, 1991. 
CASSOLA, R. Geografía del turismo: Orientaciones metodológicas. La Habana: Universidad de La Habana, 1982.

CAZES, G. Tourisme et Tiers-Monde, un bilan controversé: Les nouvelles colonies de vacances?. Tomo II, París: L’Harmattan, colección Tourismes et Société, 1992.

CENTRO INTERAMERICANO DE CAPACITACIÓN TURÍSTICA (CICATUR). Metodología de inventario Turístico. México, 1978.

DOMÍNGUEZ DE NAKAYAMA, L. Relevamiento turístico. Propuesta metodológica para el estudio de una unidad territorial. Instituto Superior de Turismo Sol. Santa Fe, Argentina, 1993.

GUZMÁN RAMOS, A. y FERNÁNDEZ, G. "EL turismo desde la geografía". En: Vera, F J. (Coord.). Análisis territorial del turismo. Barcelona, 2002.

HARVEY, D. The condition of postmodernit. An Enquiry into the Origins of Cultural Change. Cambridge, Massachusetts, 1987.

HIERNAUX, D. El giro cultural y las nuevas interpretaciones Geográficas del Turismo. GEOUSP. Espaço e Tempo, São Paulo, $\mathrm{N}^{\circ}$ 23, p. 177-187, 2008. DOI: https://doi.org/10.11606/issn.2179-0892.geousp.2008.74088

HIERNAUX, D. Geografia de Turismo. En: LINDÓN y HIERNAUX, D. (ed.) Tratado de Geografia Humana,. Barcelona: Anthoropos, Universidad Autónoma Metropolitana, pp. 401-432, 2006.

. Elementos para un análisis socio-geográfico del turismo. En: RODRIGUES, A. B. (ed.). Turismo e Geografía. Reflexões teóricas e enfoques regionais, São Paulo: Editora Hucitec, p. 39-54, 1996.

JAFARI, J. El turismo como disciplina científica. Política y Sociedad. Facultad de Ciencias Políticas y Sociología. Universidad Complutense, 2005.

Enciclopedia del turismo. Madrid: Editorial Síntesis, 2000.

LENO CERRO, F. Técnicas de evaluación del potencial turístico. Madrid: Ministerio de Industria, Comercio y Turismo, Secretaría General de Turismo, 1993.

LOZATO GIOTART, J. P. Geografía del Turismo. Del espacio contemplado al espacio consumido. Barcelona: Editorial Masson, 1990.

MESPLIER, A. y BLOC-DURAFFOUR, P. Geografía del turismo en el mundo. Madrid: Editorial Síntesis, 2000.

ORGANIZACIÓN MUNDIAL DEL TURISMO. Introducción al turismo. Madrid, 1999.

PEARCE, D. Desarrollo turístico. Su planificación y ubicación geográfica. México: Editorial Trillas, 1991. 
PINASSI, A. y ERCOLANI, P. Geografía del Turismo: análisis de las publicaciones científicas en revistas turísticas. El caso de Argentina. Cuadernos de Geografía: Revista $\begin{array}{lllllll}\text { Colombiana de } & \text { Geografía, } & \mathrm{N}^{\circ} 24 & \end{array}$ DOI: https://doi.org/10.15446/rcdg.v24n1.47778

SALINAS CHÁVEZ, E. Ordenación, Planificación y Gestión de los Espacios Turísticos: Aspectos teórico- metodológicos. En: Cappaci, A. (Editor) Turismo y Sustentabilidad. Un acercamiento multidisciplinar por el análisis del movimiento y de las estrategias de planificación territorial, Universidad degli Studi di Génova, Génova, pp. 263-273, 2002.

SANTOS, M. Espaço e método. Sao Paulo: Ed. Nobel, 1997.

Por uma economia política da cidade. São Paulo: Hucitec, 1994.

SEGUí LINÁS, M. Hacia una ciencia del turismo. Siguiendo los pasos de George Cazes. Aportes y Transferencias. Centro de Investigaciones Turísticas. Facultad de Ciencias Económicas y Sociales. Universidad Nacional de Mar del Plata. Año 10 (20), 2006.

SOJA, E. Postmodern Geographies. Verso: New York, 1989.

SOJA, E. The Spatiality of social. Life: Towards a Transformative Retheoristion. En: GREGORY, D. y UURRY, J. (eds). Social Relations and Spatial Structures, Londres, Macmillan, 1985.

VERA REBOLLO, F.; LOPEZ PALOMEQUE, F.; MARCHENA GÓMEZ, M. y ANTÓN CLAVE, S. Análisis territorial del turismo. Una nueva geografía del turismo. Barcelona: Editorial Ariel, 1997. 